\title{
Perceived barriers to utilizing maternal and neonatal health services in contracted-out versus government-managed health facilities in the rural districts of Pakistan
}

\author{
Atif Riaz ${ }^{*}$, Shehla Zaidi ${ }^{1,2}$, Asif Raza Khowaja ${ }^{2}$
}

\begin{abstract}
Background: A number of developing countries have contracted out public health facilities to the Non-Government Organizations (NGOs) in order to improve service utilization. However, there is a paucity of in-depth qualitative information on barriers to access services as a result of contracting from service users' perspective. The objective of this study was to explore perceived barriers to utilizing Maternal and Neonatal Health (MNH) services, in health facilities contracted out by government to NGO for service provision versus in those which are managed by government (non-contracted).

Methods: A community-based qualitative exploratory study was conducted between April to September 2012 at two contracted-out and four matched non-contracted primary healthcare facilities in Thatta and Chitral, rural districts of Pakistan. Using semi-structured guide, the data were collected through thirty-six Focus Group Discussions (FGDs) conducted with mothers and their spouses in the catchment areas of selected facilities. Thematic analysis was performed using NVivo version 10.0 in which themes and sub-themes emerged.

Results: Key barriers reported in contracted sites included physical distance, user charges and familial influences. Whereas, poor functionality of health centres was the main barrier for non-contracted sites with other issues being comparatively less salient. Decision-making patterns for participants of both catchments were largely similar. Spouses and mother-in-laws particularly influenced the decision to utilize health facilities.

Conclusion: Contracting out of health facility reduces supply side barriers to $\mathrm{MNH}$ services for the community served but distance, user charges and low awareness remain significant barriers. Contracting needs to be accompanied by measures for transportation in remote settings, oversight on user fee charges by contractor, and strong communitybased behavior change strategies.

Keywords: Perceived Barriers, Contracting out, Maternal and Neonatal Health (MNH)

Copyright: @ 2015 by Kerman University of Medical Sciences

Citation: Riaz A, Zaidi S, Khowaja AR. Perceived barriers to utilizing maternal and neonatal health services in contracted-out versus government-managed health facilities in the rural districts of Pakistan. Int J Health Policy Manag 2015; 4: 279-284. doi: 10.15171/ijhpm.2015.50
\end{abstract}

\section{Article History:}

Received: 22 November 2014 Accepted: 2 March 2015 ePublished: 6 March 2015
*Correspondence to: Atif Riaz

Email: atif.riaz@aku.edu

\section{Key Messages}

Implications for policy makers

- Contracting out public health facilities can be an effective strategy to improve service delivery for Maternal and Neonatal Health (MNH), however, not sufficient to improve the service utilization.

- With poor physical and financial access to health facilities in rural settings, transportation and financial safety nets need to be established.

- Cultural and customary trends strongly influence decision-making for MNH services utilization. Therefore, community-based behavior change strategies targeting mothers, spouses and mother-in-laws seem crucial.

Implications for public

The findings of this study will help improve access to Maternal and Child Health (MCH) services in remote rural communities.

\section{Background}

Sub-optimal utilization of Maternal and Neonatal Health (MNH) services remains a key factor in holding back progress towards Millennium Development Goals (MDGs) 4 and 5 in a number of developing countries (1). Review of evidence from various settings suggest that a number of factors hinder optimal use of MNH services and can be broadly categorized into: poor quality of healthcare services (2), limited knowledge of users about available services, financial barriers such as user fee, expenses on medicines and transport (3); limited physical access (4-6); or cultural practices (7). Furthermore, social dynamics such as household decision-making and women's autonomy also play a pivotal role for utilization of Maternal and Child Health $(\mathrm{MCH})$ services $(8,9)$.

Interventions and policy initiatives aiming to improve $\mathrm{MNH}$ services utilization have mainly focused on improvement of supply side at the health facilities. One such initiative commonly applied in a number of developing countries

Full list of authors' affiliations is available at the end of the article. 
including Cambodia, Guatemala, India, Bangladesh, and Afghanistan is contracting out of under performing government primary health facilities to Non-Government Organizations (NGOs) to improve facility utilization $(10,11)$. Assessments of contracting out have mainly focused on measuring changes in facility utilization rates as a result of contracting and have demonstrated improvement in the access to general healthcare services (12). Similarly, curative care utilization of health facilities has generally increased in most settings but not always resulted in an increase in promotive care, such as $\mathrm{MCH}$ provision (10). However, community perspectives on reasons of underlying improvement or lack of improvements in facility utilization have not been explored qualitatively in as much depth as in quantitative surveys $(2,13)$.

This study endeavored to explore perceived barriers for utilizing $\mathrm{MNH}$ services, in contracted out versus noncontracted primary healthcare facilities among mothers and their spouses residing in catchment areas of these facilities. Through better understanding of community experiences in response to contracting, our study findings intend to inform policy decisions regarding strategies to supplement contracting out so as to achieve optimal utilization of MNH services.

\section{Contracting in Pakistan}

Pakistan has a well-structured primary healthcare service delivery system in the form of 5,336 Basic Health Units (BHUs) and 560 Rural Health Centres (RHCs) (14). However only $22 \%$ of the population uses government health services and utilization of primary care units is particularly low (15). A number of BHUs have been contracted out in the recent years to improve health facility efficiency and utilization. The most notable initiative is People's Primary Health Care Initiative (PPHI) whereby $48 \%$ of all first level primary healthcare facilities were contracted out by government to a national NGO. Third party evaluation of PPHI revealed that contracted out BHUs were better equipped and more utilized compared to non-contracted for general health services, but no significant difference was seen for $\mathrm{MCH}$ services (16). Contracting out is now being extended on piecemeal basis to some of the remotely located RHCs. The RHC serves as a referral unit for BHU where essential and emergency obstetric and neonatal care is provided. This study was carried out in catchment communities of two contracted out and four matched non-contracted RHCs in district Thatta and Chitral, of Sindh and Khyber Pukhtunkhwa (KPK) provinces. Contracted out RHCs are located in the remotest Talukas (sub-district level) compared to the rest of the non-contracted RHCs and travel time from both contracted out RHCs to next level government healthcare facility is approximately two hours by automobile. Contracted out RHCs have been under the control of a not-for-profit NGO through a formal contractual arrangement for $\mathrm{MNH}$ services provision since 2008. The contracts were based on block grants and did not specify targets for service package. The contracted NGO had the control to introduce user fees for antenatal and delivery registration, and additional diagnostics which were not covered by the RHC budget (17).
Methods

A larger study was carried out during April to September 2012, assessing comparative advantages of contracted out government primary care facilities versus matched noncontracted facilities. Exploration of client barriers to access across contacted and non-contracted sites was one of the sub-components of the study. Social construction approach (18) was undertaken which acknowledges the importance of social dynamics, cultural practices and perceived barriers impeding access of women to $\mathrm{MNH}$ services.

\section{Settings}

The RHCs contracted out at that time were purposively selected, where as non-contracted RHCs were selected after a consultative process with district governments from the neighboring Taluka. These were matched on key demographic indicators that include Bacille Calmette Guerin (BCG) vaccination coverage, number of Lady Health workers, and physical remoteness of location.

\section{Selection of study participants}

Within the catchment population of RHCs, villages were divided into near and remote clusters ( $\leq 5$ and $>5$ kilometers) from RHC respectively and equal number of villages were randomly selected from these clusters. Nine Focus Group Discussions (FGDs) were conducted in each near and remote cluster. Within each selected village, two sets of FGDs were conducted; one with targeting pregnant/post-delivery women and another with their spouses, altogether providing a total of thirty six FGDs. Convenient sampling was used to select participants from the households of targeted villages. Participants were invited for FGDs at their convenient time and place by trained team of researchers.

The moderators who were extensively trained for FGDs, initiated discussion using a semi-structured guideline prepared with the help of review of local and global literature. The guide included questions on demographic variables and centered on client preferences for the use of MNH services, barriers to using services at RHCs, and key decision-making factors. The guide was pretested and modified according to the focus of inquiry. A free flow of information was encouraged, using probes from emergent discussion. Two note takers documented the key information. Discussions were also tape recorded after taking consent from the participants. The data were collected in the local language (Sindhi) and translated into English. Content analysis was carried out using qualitative data analysis software NVivo 10.0 in which transcripts were uploaded to provide easy and systematic retrieval of data for analysis. Tree codes corresponding to the main emergent themes were created and sub-divided into branch codes based on issues identified by the respondents.

\section{Results}

A total of 426 women and their spouses participated in FGDs. One hundred one and 265 participants were from catchment communities of contracted and non-contracted RHCs respectively, with an average of 10 participants in each FGD. About $67 \%$ of the participants in contracted and $60 \%$ in the non-contracted catchments were illiterate. Almost all of the women in both catchments were housewives with no 
source of earning. The mean ages were 39 and 29 years of men and women respectively with no significant difference of age between two catchments.

\section{Preference for facility versus home-based care}

Most of the respondents preferred facility-based services for seeking Antenatal Care (ANC), complicated childbirth and acute illnesses of neonates; but for normal childbirth they preferred home-based services provided by 'Dai' (traditional birth attendant). Mothers reported that they were more comfortable with 'Dai' while fathers were of the view that it is a cost saving option. They also perceived that postnatal visits are 'not necessary' and they seek care only in case of 'complications' or 'life threatening' conditions. Participants from catchment communities of contracted RHCs shared that they prefer to seek care from RHC rather than other local providers, while communities of non-contracted RHCs reported using private healthcare providers or approaching higher level public facilities in cities even if they had to travel long distances.

On probing into reasons for not using facility-based $\mathrm{MNH}$ services, respondents from catchment communities of contracted and non-contracted RHCs highlighted a number of barriers (Table 1).

\section{Functionality of services at health facilities}

Mothers and fathers from communities of contracted RHCs reported that services are available and are of adequate quality. Few participants reported lack of accommodation in RHCs for attendants and irksome process of advance booking for patient check-up. Communities of non-contracted RHCs stated that basic and emergency maternal and neonatal healthcare services are not available in RHCs therefore they seek care from formal and informal private providers. Most commonly cited complaints about RHCs were: non-availability of quality medicines; poor quality care; poor ambience; short functional hours of RHCs; and absenteeism of appointed staff.

\section{User charges}

Most mothers and fathers in communities who were provided services by the contracted facilities expressed that expenditures pertaining to healthcare services such as user fee was quite high to afford and the services should be free of cost. Furthermore, they were unable to meet the expenses of diagnostic services such as radiology, ultrasound scans and laboratory tests.

In catchment communities of non-contracted RHCs, participants highlighted expenses of healthcare services as a key barrier. They have to spend large amounts of money on purchase of medicines and private services, due to unavailability of quality services in RHCs.

Respondents in both catchments expressed that due to inability to pay for $\mathrm{MNH}$ services, they opt for home remedies and spiritual healers. In conditions where illness becomes severe, they borrow money from relatives and sell household assets. To repay borrowed money, monthly expenditure is curtailed by skipping meals and reducing recreational activities. Sometimes, additional loans are taken to payback the borrowed money. Respondents expressed that, in the absence of monetary resources, compromising on healthcare is the ultimate way of coping for the families for $\mathrm{MNH}$ ailments. Compromise on healthcare may be either not seeking care at all, or seeking care from local unqualified providers who are generally unable to manage complications at the community level. Though they realized that compromising healthcare for $\mathrm{MNH}$ is a matter of 'life and death', yet they became helpless in such a condition.

Table 1. Key barriers to MNH services utilization

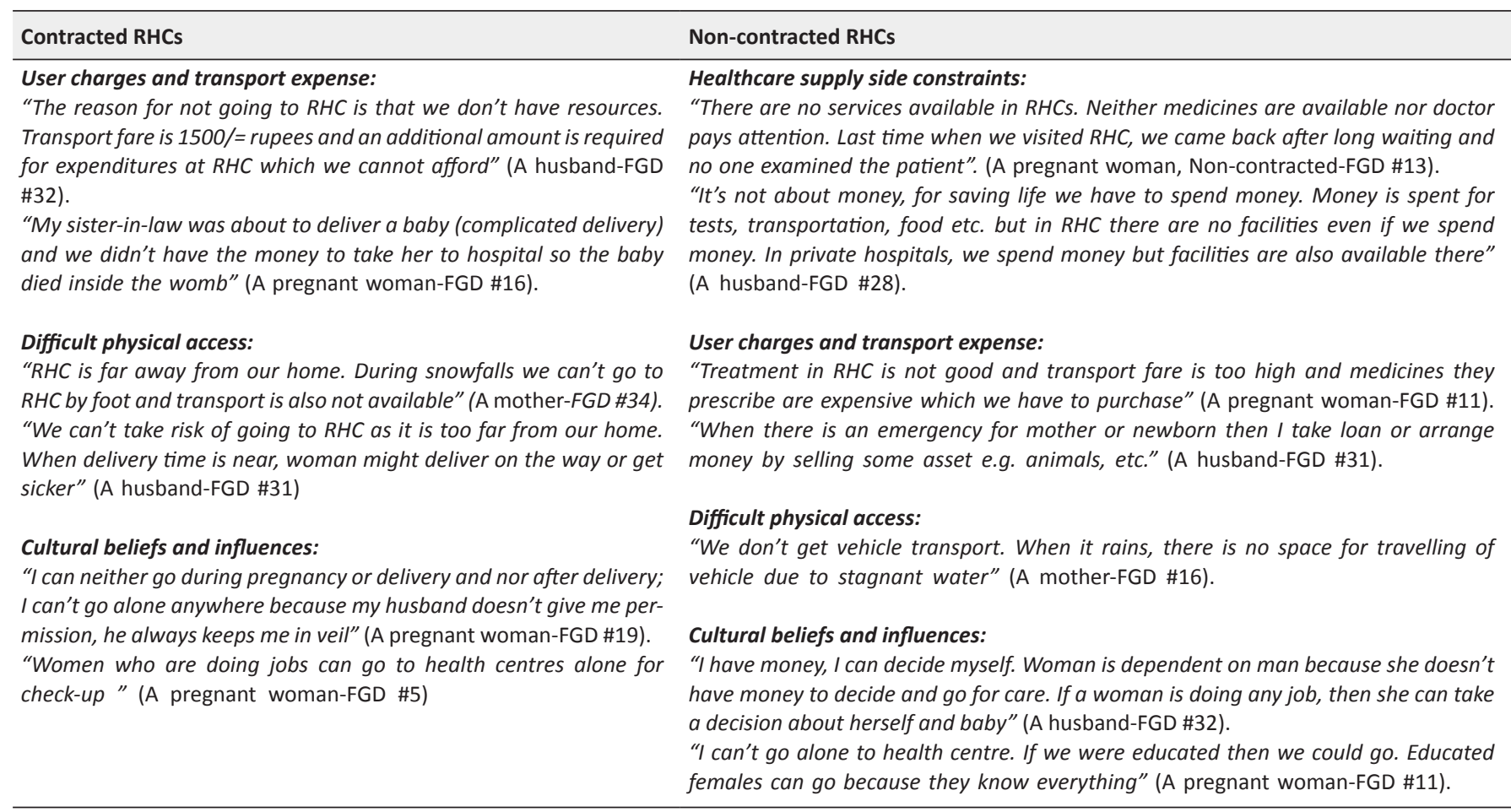

$\mathrm{MNH}=$ Maternal and Neonatal Health, $\mathrm{RHC}=$ Rural Health Centre; FGD= Focus Group Discussion. 
Physical distance and transport issues

Respondents of both catchment communities reported long distance from RHCs as another important influence for not availing ANC, normal delivery, Postnatal Care (PNC), and well-baby care. Few respondents also expressed that scanty transport and resulting high expenditure, difficult terrain, poor condition of roads, and unfavorable weather conditions such as rains and snowfall sometimes influence their decision to use facility-based services. They were also afraid of facing complications on the way to RHC as it might take long for them to reach there.

\section{Cultural beliefs and influences}

In both catchments, husband being head of the household and responsible for earning and keeping money, is the main authority who decides for utilization of routine $\mathrm{MNH}$ services as well as maternal or newborn emergency. Father and mother-in-law being elder members of the family take decision when husband is not available at home. Women reported that their mothers-in-law influence decision for home delivery based on their own experiences. According to their mothers-in-law, delivery is a 'normal process' and there is no need to go to a centre. Few male participants perceived that involving women in decision-making is against 'Shariah' (Islamic laws).

Most women expressed that although they could not participate in decision-making even for their own health, they were still assertive for their children and sought care for neonates whenever needed. They also felt that if they were educated or had an independent source of earning, they could decide for their own health too.

\section{Discussion}

Care seeking behavior for $\mathrm{MNH}$ is a complex interplay of access factors and decision-making dynamics at the household level, as seen in this study and borne out by global literature $(19,20)$. Our context was of remote rural settings, and findings are interpreted within this contextual setting. Communities preferred using facility-based services for ANC, complicated delivery and acute illnesses of neonates in contracted centres while those in non-contracted, tended to bypass government facilities or abstained from seeking care. Poor functionality of services in government managed health centres led to clients bypassing facilities for MNH services. This finding confirms with the existing evidence that poorly functioning government facilities is a motivating factor to deliver at home (2), purchase services from healthcare shop (21), or turn to higher level facilities for primary care (22). Facility related constraints were only minor issues in communities residing in contracted sites but were a noticeable constraint in non-contracted sites. However, facility-based services for normal delivery, post natal and well-baby care were not sought by both communities, which can be explained by a variety of other factors highlighted in this study including: user charges, distance coupled by dearth of transport, and cultural practices.

Financial constraints due to user charges was an issue in accessing contracted out facilities due to high charges for diagnostics and extra services, while government managed facilities had lower range and poorer quality of services but were free. Informal providers such as 'Dai' charge nominal fee and provides services at doorstep making it more convenient for clients to forego facility-based services (23). Caution needs to be exercised by the government in negotiating service package in contracts and means of budgetary support. Prior determination of contractual unit costs and oversight on charges remains an unexplored area of contracting.

Long distances and scanty transport resulting in high transport charges remained a major bottleneck to availing services in both contracted and non-contracted sites. This resulted in foregoing of antenatal and well-baby care visits, limiting clients to mainly seek care at the time of delivery related complication or acute illnesses of neonates. Distance and transport issues as barriers to utilization of maternal health services are also reported by other studies $(19,23)$, however this has not been studied in the context of contracting out healthcare services.

Cultural influences and concept of 'normality' (no need to seek care unless there is an emergency or complication) is deeply rooted in Pakistani society where use of preventive services is not deemed necessary. Similar findings have been reported from other low- and middle-income countries where women did not feel the need for professional care unless emergency or complication arouses $(2,20,24)$. Furthermore, men and elder in-laws are found to have paramount role in decision-making and determining needs of women which is consistent with other studies reporting that close social relations and social structures influence decision-making $(23,25)$. This insight suggests that awareness building measures and Behaviour Change Communication (BCC) strategies must target husbands and in-laws. A study from Nepal documented that women who received antenatal health education with their husbands were more likely to seek post-partum care and birth preparedness than those who received education alone (26).

In a nutshell, contracting out may improve service utilization at heath centres, as has been seen in a number of studies, but not necessarily translate into higher population level coverage rates (27), especially for promotive services such as $\mathrm{MNCH}$. Hence, residual constraints of clients for seeking healthcare needs to be addressed in parallel to contracting. A combination of demand and supply side incentives, as seen in Nicaragua, has improved utilization of preventive services among the poor and our study favors a combined approach (28). In remote rural settings measures are needed at facilitating transport access and a number of measures have been identified including community revolving funds for transport, transporter-community links facilitated by NGOs, and transport vouchers (29-31). BCC has proved to be effective for birth preparedness and newborn care (32), and in this case calls for inclusion of husbands and inlaws. Furthermore, programs to economically and socially empower women such as microfinance schemes can enhance their decision-making power for MNH services $(33,34)$. However these are larger overarching development agenda beyond the scope of health sector.

\section{Strengths and limitations}

The strength of the study is in bringing a qualitative community perspective to a supply side reform that has 
usually been examined through quantitative assessment. Second, we explored constraints across a range of $\mathrm{MNH}$ services rather than focus on merely delivery as has been the case with most studies exploring delays $(20,35)$. Third, within the remits of qualitative research we compared perspectives across both contracted and non-contracted sites. The study also has certain limitations. First, FGD was the only method of information collection while other qualitative methods such as in-depth interviews were not applied which could have helped in triangulation. However, it would not influence study findings or their interpretation for given objectives as the aim was to explore perspective of groups rather than the individual. Second, mothers-in-law were not invited in the FGDs, as study findings show that their stake in decisionmaking is high, important insights could have been obtained. The study was confined to rural remote setting in Pakistan and cannot be generalized to less remote low-income settings.

\section{Conclusion}

Contracting out of health facility reduces supply side barriers to MNH services for the community served but distance, user charges and low awareness remain significant barriers. These are specially seen hindering the use of delivery and PNC visits by clients. Accompanying measures are needed to target male decision-makers for behavior change communication; arrangement of transport funds, and negotiating budget and service package contracts to reduce user charges.

\section{Acknowledgments}

This research was funded by the Maternal and Newborn Health Programme - Research and Advocacy Fund (RAF), Pakistan. We would like to thank all participants for their valuable contribution to study and officials for their support. We would also like to thank Dr. Shiraz Hashmi for proof reading manuscript and providing valuable feedback.

\section{Ethical issues}

Ethical approval was obtained from Ethics Review Committee (ERC) of the Aga Khan University Karachi, Pakistan and Research Ethics Committee of National Bioethics Committee, Pakistan, as part of a larger study. Written informed consents were obtained from all participants prior to FGDs and responses were coded anonymously.

\section{Competing interests}

Authors declare that they have no competing interests.

\section{Authors' contributions}

SZ conceptualized and supervised the study. AR reviewed literature, analyzed data, and wrote manuscript. ARK contributed to data analysis, interpretation, and manuscript writing.

\section{Authors' affiliations}

${ }^{1}$ Department of Community Health Sciences, Aga Khan University, Karachi, Pakistan. ${ }^{2}$ Women and Child Health Division, Aga Khan University, Karachi, Pakistan.

\section{References}

1. Babalola S, Fatusi A. Determinants of use of maternal health services in Nigeria-looking beyond individual and household factors. BMC Pregnancy Childbirth 2009; 9: 43. doi: 10.1186/1471-2393-9-43

2. Griffiths $P$, Stephenson R. Understanding users' perspectives of barriers to maternal health care use in Maharashtra, India. $J$ Biosoc Sci 2001; 33: 339-59. doi: 10.1017/s002193200100339x

3. Nanda P. Gender dimensions of user fees: Implications for women's utilization of health care. Reprod Health Matters 2002; 10: 127-34. doi: 10.1016/s0968-8080(02)00083-6

4. Onah HE, Ikeako LC, Iloabachie GC. Factors associated with the use of maternity services in Enugu, southeastern Nigeria. Soc Sci Med 2006; 63: 1870-8. doi: 10.1016/j.socscimed.2006.04.019

5. Amooti-Kaguna B, Nuwaha F. Factors influencing choice of delivery sites in Rakai district of Uganda. Soc Sci Med 2000; 50: 203-13. doi: 10.1016/s0277-9536(99)00275-0

6. McNamee P, Ternent L, Hussein J. Barriers in accessing maternal healthcare: evidence from low-and middle-income countries. Expert Rev Pharmacoecon Outcomes Res 2009; 9: 41-8. doi: 10.1586/14737167.9.1.41

7. Nabukera SK, Batwala VK, Mulogo EM, Barry S, Salihu HM. Use of postpartum health services in rural Uganda: knowledge, attitudes and barriers. J Community Health 2006; 31: 84-93. doi: 10.1007/s10900-005-9003-3

8. Fotso JC, Ezeh AC, Essendi H. Maternal health in resourcepoor urban settings: how does women's autonomy influence the utilization of obstetric care services? Reprod Health 2009; 6: 9. doi: 10.1186/1742-4755-6-9

9. Furuta M, Salway S. Women's position within the household as a determinant of maternal health care use in Nepal. Int Fam Plan Perspect 2006; 32: 17-27. doi: 10.1363/3201706

10. Zaidi S, Salam R, Rizvi SS, Ansari S, Bhutta Z. Public Private Partnerships for Improving Maternal \& Neonatal Health Service Delivery. Islamabad: Research and Advocacy Fund, British Council; 2013.

11. Zaidi S, Bhutta, Z, Shaikh S, Salam R, Rahim A. Landscaping finance support platforms for the improvement of Basic and Emergency obstetric care. WHO; 2012. (Unpublished report)

12. Liu X, Hotchkiss DR, Bose S. The effectiveness of contractingout primary health care services in developing countries: a review of the evidence. Health Policy Plann 2008; 23: 1-13. doi: 10.1093/heapol/czm042

13. Matsuoka S, Aiga H, Rasmey LC, Rathavy T, Okitsu A. Perceived barriers to utilization of maternal health services in rural Cambodia. Health Policy 2010; 95: 255-63. doi: 10.1016/j. healthpol.2009.12.011

14. Ministry of Finance (MoF). Health and Nutrition. Economic survey 2006-7. Government of Pakistan. Available from: http:// www.finance.gov.pk/survey/chapters/12-Health.pdf

15. Pakistan Bureau of Statistics. Pakistan Social and Living Standards Measurement Survey (PSLM). Islamabad; 2012-3.

16. Martinez J, Pearson M, England R. Third-Party Evaluation of the PPHI in Pakistan. Technical Resource Facility and Sosec; 2010. (Unpublished document)

17. Hatcher P, Shaikh S, Fazli H, Zaidi S, Riaz A. Provider cost analysis supports results-based contracting out of maternal and newborn health services: an evidence-based policy perspective. BMC Health Serv Res 2014; 14: 459. doi: 10.1186/1472-696314-459

18. Burr V. Social constructionism. London: Psychology Press; 2003.

19. Gage AJ. Barriers to the utilization of maternal health care in rural Mali. Soc Sci Med 2007; 65: 1666-82. doi: 10.1016/j. socscimed.2007.06.001

20. Mrisho M, Obrist B, Schellenberg JA, Haws RA, Mushi AK, Mshinda $\mathrm{H}$, et al. The use of antenatal and postnatal care: perspectives and experiences of women and health care providers in rural southern Tanzania. BMC Pregnancy Childbirth 2009; 9: 10. doi: 10.1186/1471-2393-9-10

21. Uzma A, Underwood P, Atkinson D, Thackrah R. Postpartum health in a Dhaka slum. Soc Sci Med 1999; 48: 313-20. doi: 10.1016/s0277-9536(98)00319-0 
22. Atkinson S, Ngwengweb A, Macwan'gic M, Ngulubed TJ, Harphame T, O'Connellf A. The referral process and urban health care in sub-Saharan Africa: the case of Lusaka, Zambia. Soc Sci Med 1999; 49: 27-38. doi: 10.1016/s0277-9536(99)00072-6

23. Shaikh BT, Haran D, Hatcher J. Where do they go, whom do they consult, and why? Health-seeking behaviors in the northern areas of Pakistan. Qual Health Res 2008; 18: 747-55. doi: 10.1177/1049732308317220

24. Choudhury N, Ahmed SM. Maternal care practices among the ultra poor households in rural Bangladesh: a qualitative exploratory study. BMC Pregnancy Childbirth 2011; 11: 15. doi: 10.1186/1471-2393-11-15

25. Aboagye E. Access Opportunities, Social Structures and Maternal Health Seeking Behaviour in Bosomtwe District. Norwegian University of Science and Technology; 2010.

26. Mullany BC, Becker S, Hindin MJ. The impact of including husbands in antenatal health education services on maternal health practices in urban Nepal: results from a randomized controlled trial. Health Educ Res 2007; 22: 166-76.

27. Zaidi S, Rabbani F, Riaz A, Pradhan N, Hatcher P. Improvement in Access and Equity for Maternal and Newborn Health Services: Comparative Advantages of Contracted out versus NonContracted Facilities. Islamabad: Research and Advocacy Fund, British Council; 2013.

28. Regalia F, Castro L. Performance-Based Incentives for Health: Demand-and Supply-Side Incentives in the Nicaraguan Red de Proteccion Social. Center for Global Development Working Paper; 2007.
29. Ir P, Horemans D, Souk N, Van Damme W. Using targeted vouchers and health equity funds to improve access to skilled birth attendants for poor women: a case study in three rural health districts in Cambodia. BMC Pregnancy Childbirth 2010; 10: 1. doi: 10.1186/1471-2393-10-1

30. Nguyen HT, Hatt L, Islam M, Sloan NL, Chowdhury J, Schmidt $\mathrm{JO}$, et al. Encouraging maternal health service utilization: an evaluation of the Bangladesh voucher program. Soc Sci Med 2012; 74: 989-96. doi: 10.1016/j.socscimed.2011.11.030

31. Essien E, Ifenne D, Sabitu K, Musa A, Alti-Mu'azu M, Adidu V, et al. Community loan funds and transport services for obstetric emergencies in northern Nigeria. Int J Gynaecol Obstet 1997; 59: S237-44. doi: 10.1016/s0020-7292(97)00171-9

32. Baqui $\mathrm{AH}$, El-Arifeen $\mathrm{S}$, Darmstadt $\mathrm{GL}$, Ahmed $\mathrm{S}$, Williams EK, Seraji HR, et al. Effect of community-based newborn-care intervention package implemented through two service-delivery strategies in Sylhet district, Bangladesh: a cluster-randomised controlled trial. Lancet 2008; 371: 1936-44. doi: 10.1016/s01406736(08)60835-1

33. Abdullah S, Tworoger T, Tworoger $\mathrm{L}$. Targeted microfinance and women involvement in household decision-making: evidence from Bangladesh. Allied Academies 2008; 15: 348.

34. Swain RB, Wallentin FY. Does microfinance empower women? Evidence from self-help groups in India. International Review Applied Economics 2009; 23: 541-56.

35. Ensor T, Cooper S. Overcoming barriers to health service access: influencing the demand side. Health Policy Plan 2004; 19: 69-79. doi: 10.1093/heapol/czh009 